Research Paper

\title{
Pain Characteristics after Total Laparoscopic Hysterectomy
}

\author{
Jong Bum Choi ${ }^{1}$, Kyeongjin Kang${ }^{2}$, Mi Kyung Song ${ }^{3}$, Suhyun Seok${ }^{1}$, Yoon Hee Kim4, and Ji Eun Kim ${ }^{\bowtie}$ \\ 1. Department of Anesthesiology and Pain Medicine, Ajou University School of Medicine, Suwon, Republic of Korea \\ 2. Department of Anatomy and Cell Biology, School of Medicine, Sungkyunkwan University, Seoul, Republic of Korea \\ 3. Department of Research Affairs, Biostatistics Collaboration Unit, Yonsei University College of Medicine, Seoul, Republic of Korea \\ 4. Department of Anesthesiology and Pain Medicine, Yonsei University College of Medicine, Seoul, Republic of Korea
}

$\square$ Corresponding author: Ji Eun Kim, MD, PhD, Department of Anesthesiology and Pain Medicine, Ajou University School of Medicine, 164, World cup-ro, Yeongtong-gu, Suwon 16499, Republic of Korea. Phone: +82.31-219-5575; FAX: +82.31-219-5579; E-mail: beye98@aumc.ac.kr

(C) Ivyspring International Publisher. Reproduction is permitted for personal, noncommercial use, provided that the article is in whole, unmodified, and properly cited. See http://ivyspring.com/terms for terms and conditions.

Received: 2016.04.17; Accepted: 2016.06.20; Published: 2016.07.05

\begin{abstract}
Background. Total laparoscopic hysterectomy (TLH) causes various types of postoperative pain, and the pain pattern has not been evaluated in detail to date. This prospective observational study investigated the types of postoperative pain, intensity in the course of time, and pain characteristics during the first postoperative $72 \mathrm{hr}$ after TLH.

Methods. Sixty four female patients undergoing TLH were enrolled, which finally 50 patients were included for the data analyses. The locations of pain included overall pain, abdominal visceral and incisional pains, shoulder pain, and perineal pain. Assessments were made at rest and in motion, and pain level was scored with the use of the $100 \mathrm{~mm}$ visual analog scale. The pain was assessed at baseline, and at postoperative $30 \mathrm{~min}, 1 \mathrm{hr}, 3 \mathrm{hr}, 6 \mathrm{hr}, 24 \mathrm{hr}, 48 \mathrm{hr}$, and $72 \mathrm{hr}$.

Results. Overall, visceral, and incisional pains were most intense on the day of operation and then decreased following surgery. In contrast, shoulder pain gradually increased, peaking at postoperative $24 \mathrm{hr}$. Shoulder pain developed in $90 \%$ of all patients (44/50). It was not more aggravated in motion than at rest, in comparison with other pains, and right shoulder pain was more severe than left shoulder pain $(p=0.006)$. In addition, the preoperative exercise habit of patients increased the threshold of shoulder pain. Most patients (46/50) had perineal pain, which was more severe than abdominal pain in approximately $30 \%$ of patients $(17 / 50)$.

Conclusion. Pain after TLH showed considerably different duration, severity, and characteristics, compared with other laparoscopic procedures. Shoulder pain was most intense at postoperative $24 \mathrm{hr}$, and the intensity was associated with the prior exercise habit of patients and the high level of analgesic request.
\end{abstract}

Key words: Exercise habit; Laparoscopic hysterectomy; Postoperative pain; Shoulder pain

\section{Introduction}

Total laparoscopic hysterectomy (TLH) is a commonly performed gynecological procedure. Compared to traditional abdominal hysterectomy, it has many advantages, such as less postoperative morbidity, shorter hospitalization, and faster recovery. [1] In addition to incisional pain, TLH may cause different types of pain that result from various perioperative predicaments, including pneumoperitoneum, stretching of the intraabdominal cavity, blood left in the abdomen, and dissection of the pelvic region. Moreover, patients undergoing laparoscopic approaches, that have the reputation of being less painful, were found to receive inadequate pain relief and experience high levels of postoperative pain rather than aggressive major surgeries. [2] As such, the postoperative pain after TLH is often difficult to control, which leads to increased opioid use and delayed discharge from hospital, despite 
being a minimally invasive laparoscopic surgery. [3]

The detection of early pain within the first 3 days is important as timely treatment of intense acute postoperative pain may reduce the risk of developing chronic pain. [4-7] In addition, procedure-specific analysis of characteristics on early postoperative pain is indispensable to proper analgesic use and optimal dynamic pain relief, allowing fast convalescence. [8,9] The pain characteristics have been previously described in the literature concerning laparoscopic cholecystectomy, laparoscopic ventral hernia repair, laparoscopic inguinal hernia repair, laparoscopic fundoplication, neuro-surgeries, and caesarean section. [10-16]

Compared with other gynecological laparoscopic procedures, TLH requires longer operation time and is thus exposed to more tissue manipulation. Also, the head-down position during surgery may aggravate pain in the shoulder in conjugation with carbon dioxide $\left(\mathrm{CO}_{2}\right)$ pneumoperitoneum. Therefore, pain patterns after TLH were expected to have intensities and time courses incomparable to the postoperative pain following other types of surgery, which do not take a head-down position, such as laparoscopic cholecystectomy.

The purpose of this prospective descriptive study was to characterize the early pain characteristics during the postoperative $72 \mathrm{hr}$ after total laparoscopic hysterectomy.

\section{Materials and Methods}

\section{Ethics}

This single-center prospective observational study was conducted on patients undergoing elective TLH between January 2013 and June 2013 at Severance Hospital, Seoul, Republic of Korea. Ethical approval for this study was provided by the institutional review board of Severance Hospital, Yonsei University Health System, Seoul, Republic of Korea (IRB number: 4-2012-0871). This study was registered with ClinicalTrials.gov (identified: NCT 01838382). Written informed consent was obtained from all participants.

\section{Participants}

A total of 64 adult patients were enrolled. The inclusion criteria were women aged 20-75 years who underwent elective hysterectomy due to myoma, cervical dysplasia, adenomyosis, endometriosis, ovarian tumor, vulva cancer, and could understand Korean. The exclusion criteria were presence of multifocal tumors, American Society of Anesthesiologists (ASA) physical status $ш$ or greater, psychiatric problems, cooperation difficulty, use of steroids or immunosuppressant drugs, regular use of opioid, history of shoulder trauma or surgery, prior breast cancer surgery, peripheral neuropathy, or intraoperative conversion to open surgery.

\section{Evaluations, definitions and pain management}

The locations of pain were overall, abdomen, shoulder and perineum. Abdominal pain was assessed as 2 components such as visceral pain and incisional pain. Shoulder pain was measured as overall, right, and left. Pain assessments were made at rest and in motion. The pain was scored with the use of a $100 \mathrm{~mm}$ visual analog scale (VAS); whereby no pain is 0 and the worst possible pain is 100 .

The pain was analyzed preoperatively (at baseline) with data sets of postoperative $30 \mathrm{~min}, 1 \mathrm{hr}$, $3 \mathrm{hr}, 6 \mathrm{hr}, 24 \mathrm{hr}, 48 \mathrm{hr}$, and $72 \mathrm{hr}$. Because sitting or walking was considered to be challenging for the patients at times of postoperative $30 \mathrm{~min}$ and $1 \mathrm{hr}$, abdominal pain in motion was assessed by just bending the knees in supine position, and shoulder pain in motion was assessed by turning the arm towards the head.

"Exercise habit" was applied to ordinary exercise before surgery, which included fitness, swimming, golf, yoga, aerobics and climbing. Walking is included into "exercise habit" as patients regarded it confidently as exercise. The days of hospitalization and postoperative complications were evaluated. Age, operation time, and anesthetic time were divided into 2 groups on the basis of each mean value; 50 years, $73.5 \mathrm{~min}, 110 \mathrm{~min}$, respectively. Overweight and obesity were defined as BMIs of more than 25 or $30 \mathrm{~kg} / \mathrm{m}^{2}$, respectively, and motion was defined as tossing and turning, bending of legs, or sitting up.

For postoperative pain control, intravenous (IV) patient-controlled analgesia (PCA) was administered to all patients. Fentanyl of PCA was continuously infused as $0.2 \mu \mathrm{g} / \mathrm{kg} / \mathrm{hr}$ for $48 \mathrm{hr}$ using Accufuser-Plus (WooYoung Medical, Seoul, Korea). In the postanesthetic care unit (PACU), patients with pain higher than VAS 50 received the IV fentanyl 50 $\mu \mathrm{g}$ as additional analgesic for immediate postoperative pain management, up to $150 \mu \mathrm{g}$ in total. The degree of nausea was also evaluated (1: none, 2 : mild, 3: moderate, 4: severe) and the presence of vomiting was checked. Patients with either vomiting or score 3 to 4 nausea received anti-emetics, such as macperan or ondansetron, and patients with shivering received meperidine. In ward, all patients were ordered a standardized postoperative pain regimen. Pain scores were regularly examined by ward nurses. The patients received the IV PCA basically, but were also administrated with IV ketorolac $30 \mathrm{mg}$ or IV tramadol $50 \mathrm{mg}$ as 
supplemental analgesics, when requesting the analgesics or appealing the pain higher than VAS 50.

\section{Anesthesia and Perioperative Management}

Patients were premedicated with IV midazolam $0.02 \mathrm{mg} / \mathrm{kg}$. On arrival in the operating room, standard monitors with bispectral index system were applied. General anesthesia was induced with IV propofol $1.5 \mathrm{mg} / \mathrm{kg}$ and remifentanil $0.3 \mu \mathrm{g} / \mathrm{kg}$. Rocuronium bromide $0.6 \mathrm{mg} / \mathrm{kg}$ was used to facilitate orotracheal intubation. Patients were mechanically ventilated to maintain end-tidal $\mathrm{CO}_{2}$ between 35-40 $\mathrm{mmHg}$ at $50 \%$ inspired oxygen with air. Anesthesia was controlled with continuous infusion of remifentanil at a rate of $0.01-0.05 \mu \mathrm{g} / \mathrm{kg} / \mathrm{min}$ and desflurane at 6-7 vol\%. A urinary catheter was inserted to measure urine output. Lactate Ringer's solution or normal saline was infused at a constant rate of $10 \mathrm{~mL} / \mathrm{kg} / \mathrm{h}$. When blood loss was more than $500 \mathrm{~mL}, 6 \%$ hydroxyethyl starch solution (Voluven, Fresinius Kabi, Bad Homberg, Germany) was administered. Anesthesia was maintained within mean arterial pressure (MAP) of $70-80 \mathrm{mmHg}$ and urine output more than $1 \mathrm{ml} / \mathrm{kg}$ during the surgery. At the end of surgery, patients were extubated and transferred to PACU. The urinary catheter was removed by the evening of postoperative day (POD) 1.

\section{Operative Procedures}

All procedures were performed by 3 surgeons during the study period. After performing lithotomy position, the shoulder braces were applied and then reverse Trendelenburg position was performed at $30^{\circ}$. Laparoscopic procedures were performed with 4 abdominal trocar sites. Laparoscopy was performed using $\mathrm{CO}_{2}$ as the distension medium, which was introduced through a Veress needle placed intraumbilically. The abdominal pressure was monitored by the delivery of a tidal volume of gas. The gas pressure was set at $12 \mathrm{mmHg}$ during the procedure, and ventilation was adjusted to maintain end-tidal $\mathrm{CO}_{2}$ under $45 \mathrm{mmHg}$.

TLH with or without salpingo-oorectomy was carried out. A uterine manipulator via vaginal access was used for uterine manipulation, colpotomy, and vaginal occlusion. The vaginal vault was repaired with intracorporeal suturing. A drain was inserted when needed.

\section{Statistical analysis}

Values are presented as mean \pm standard deviation, median [interquartile range] or number (\%). Normality was assessed with the KolmogorovSmirnov test. Repeatedly measured data, including overall, incisional, visceral, and shoulder pain, were analyzed using a linear mixed model with compound symmetry; for the comparison of pain at rest and in motion, the comparison of pain at each sites, and for comparison of pain in 2 groups according to age, history of cesarean or vaginal delivery, operation time, anesthetic time, overweight, obesity, and exercise habit was used. Data were then corrected by false discovery rate (FDR) method. [17] Statistical analyses with $\mathrm{p}<0.05$ were considered significant. Statistics were implemented using SAS (Statistical Analysis System, 9.2 version Inc., Cary, NC, USA).

\section{Results}

Among 64 patients, 14 patients were excluded, and a total of 50 patients were included as shown in Figure 1. Patient characteristics and data from the perioperative period are summarized in Table 1.

Table 1. Demographic and clinical characteristics of study patients.

\begin{tabular}{|c|c|}
\hline Variables & $n=50$ \\
\hline Age (years) & $49.26 \pm 7.88$ \\
\hline Weight (kg) & $60.13 \pm 8.97$ \\
\hline Height (cm) & $157.99 \pm 4.29$ \\
\hline Body mass index $\left(\mathrm{kg} / \mathrm{m}^{2}\right)$ & $24.15 \pm 3.94$ \\
\hline \multicolumn{2}{|l|}{ Delivery history } \\
\hline Cesarean & $13(26 \%)$ \\
\hline Vaginal & $38(76 \%)$ \\
\hline Both & $4(8 \%)$ \\
\hline Exercise habit history & $20(40 \%)$ \\
\hline \multicolumn{2}{|l|}{ Diagnosis } \\
\hline Myoma & $30(60 \%)$ \\
\hline Cervical dysplasia & $14(28 \%)$ \\
\hline Ovarian cyst & $10(20 \%)$ \\
\hline Adenomyosis & $12(24 \%)$ \\
\hline Endometriosis & $4(8 \%)$ \\
\hline Vulva cancer & $1(2 \%)$ \\
\hline Ovarian tumor & $1(2 \%)$ \\
\hline Hydrosalpinx & $1(2 \%)$ \\
\hline \multicolumn{2}{|l|}{ Operation } \\
\hline TLH & $23(46 \%)$ \\
\hline $\mathrm{TLH}+\mathrm{BSO}$ & $23(46 \%)$ \\
\hline TLH + RSO or LSO & $4(8 \%)$ \\
\hline Additional salpingectomy & $6(12 \%)$ \\
\hline Additional cystectomy & $4(8 \%)$ \\
\hline Uterine weight (gm) & $239.62 \pm 149.41$ \\
\hline Drain insertion & $6(12 \%)$ \\
\hline Operation time (min) & $73.5[30-231]$ \\
\hline Anesthetic time (min) & $110[75-265]$ \\
\hline \multicolumn{2}{|l|}{ Post-anesthetic care unit } \\
\hline Nausea $(1: 2: 3: 4)$ & $50(38: 3: 5: 4)$ \\
\hline Vomiting & 0 \\
\hline Dizziness & $1(2 \%)$ \\
\hline Shivering & $1(2 \%)$ \\
\hline Additional medicine & $7(14 \%)$ \\
\hline Day of hospital & $5.04 \pm 2.04$ \\
\hline
\end{tabular}

Data are presented as means \pm standard deviation, median [interquartile range], or numbers (\%).

BMI, body mass index; BSO, bilateral salpingo-oophorectomy; LSO, left salpingo-oophorectomy; RSO, right salpingo-oophorectomy; TLH, total laparoscopic hysterectomy. 


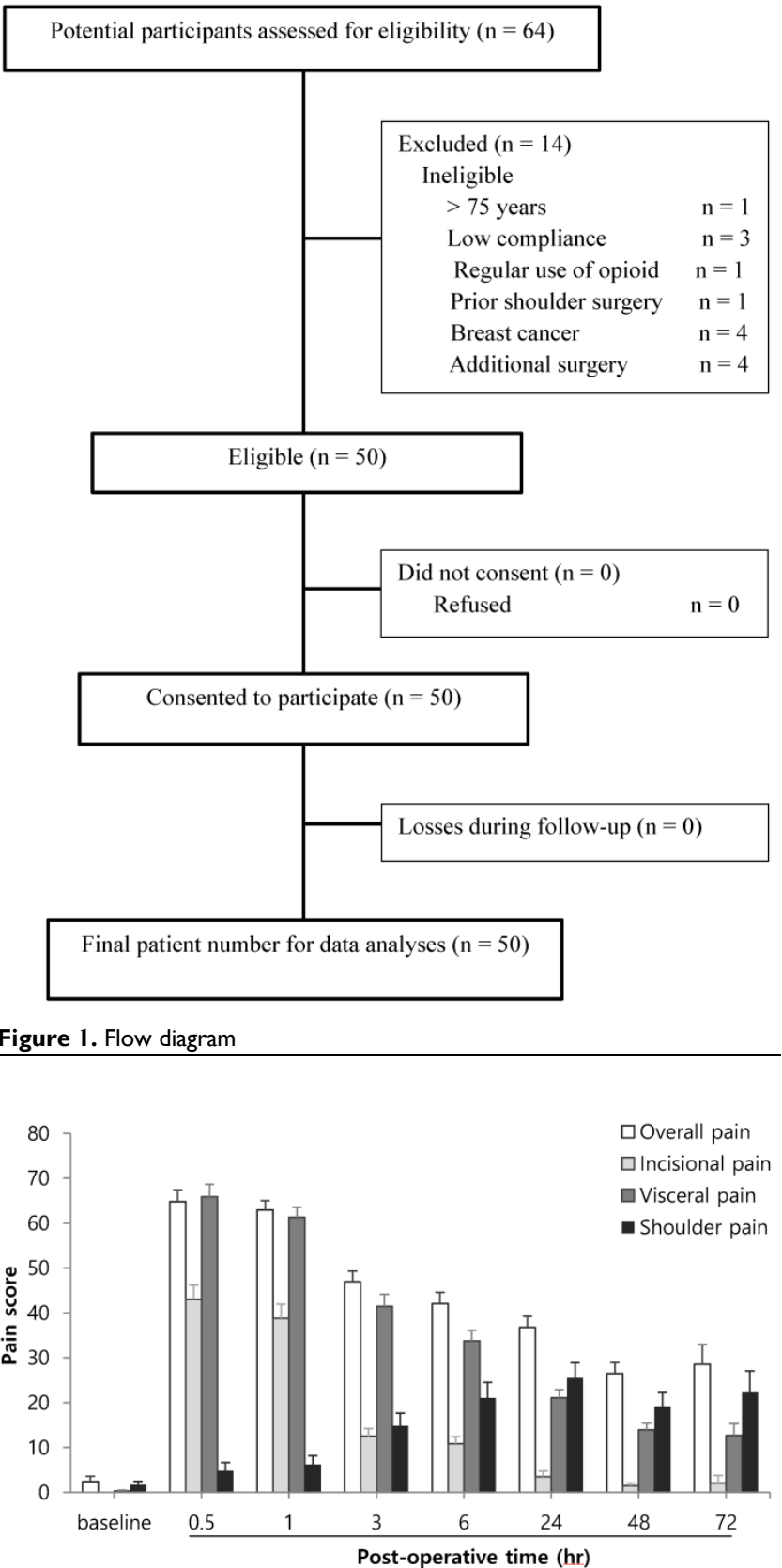

Figure 2. Pains after total laparoscopic hysterectomy. The pain score was expressed using a $100 \mathrm{~mm}$ visual analog scale (VAS).

Figure 2 demonstrates the 2 different patterns of pain progression, in which pain was actively exhibited in the early half or the late half of the follow up period during postoperative $72 \mathrm{hr}$. Overall pain, abdominal visceral and incisional pains were high in the early half and then decreased. In contrast, shoulder pain gradually increased and was high toward the late half, peaking at postoperative $24 \mathrm{hr}$.

Age, history of cesarean or vaginal delivery, operation time, anesthetic time, overweight, or obesity did not show significant differences in overall pain, abdominal incisional and visceral pains, or shoulder pain. In contrast, the patients with various exercise habits $(n=20)$ showed lower overall pain scores compared to patients with no exercise habits $(\mathrm{n}=30)$ at postoperative $6 \mathrm{hr}$ (Figure 3A). The patients with exercise habits $(n=20)$ also showed lower shoulder pain scores compared to patients with no exercise habits $(n=30)$ at postoperative $24 \mathrm{hr}$ (Figure 3C), while the visceral pain was not alleviated (Figure 3B).
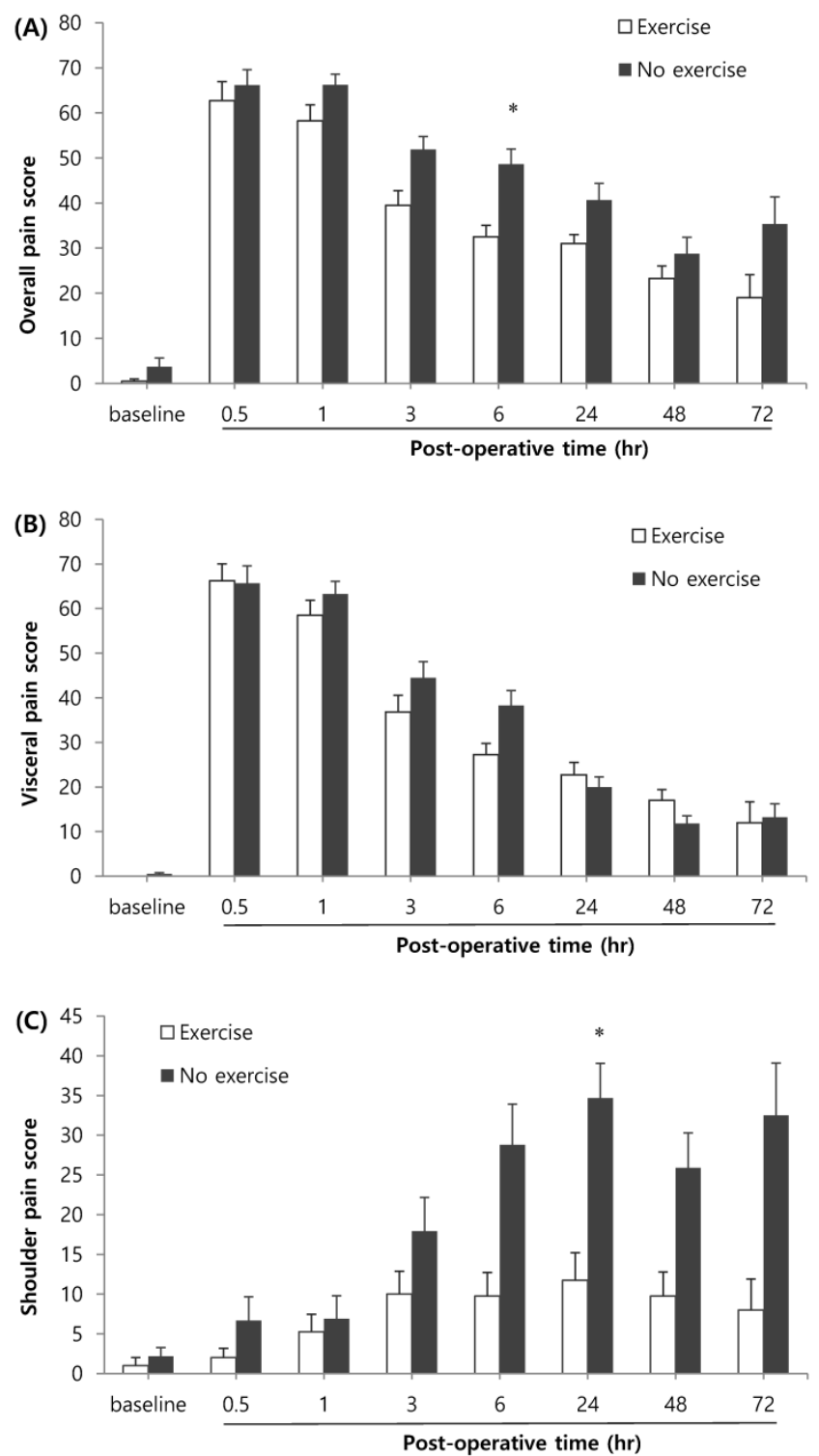

Figure 3. Effects of exercise habit on overall pain (A), visceral pain (B), and shoulder pain $(C)$. $*$ Indicates a statistically significant difference compared with the control group $(p<0.05)$. The pain score was expressed using a $100 \mathrm{~mm}$ visual analog scale (VAS).

Approximately $90 \%$ of patients $(44 / 50)$ noted shoulder pain, and $40 \%$ of patients (18/44) among them exhibited pain higher than VAS 50. Shoulder pain was most severe at postoperative $24 \mathrm{hr}$, and right shoulder pain was more severe than left shoulder pain (Figure $4, p=0.006$ ). In addition, we thought that 
the elderly patients had the more severe pain compared with the young patients, but there was no significant difference among age groups regarding the severity of shoulder pain. At postoperative $48 \mathrm{hr}$, the analgesics were administrated to 22 patients, of which $73 \%$ patients $(16 / 22)$ complained of shoulder pain at a similar degree to, or stronger than, abdominal pain.

Incisional pain was more aggravated in motion than at rest on the operation day and postoperative 24 hr; visceral pain was aggravated in motion from operation day to postoperative $72 \mathrm{hr}$. In contrast, motion did not aggravate shoulder pain. The shoulder pain at rest was not significantly different from that in motion.

$92 \%$ of patients $(46 / 50)$ had perineal pain at POD 1 , which was developed by surgical procedure and aggravated by foley catheter. In approximately $30 \%$ of patients $(17 / 50)$, perineal pain was more severe than abdominal pain.

Figure 5 shows the requested analgesic uses on operation day and POD 1-3. Analgesic consumption increased at 3 time points; (i) period of PACU arrival and postoperative $30 \mathrm{~min}$, (ii) period of postoperative $1 \mathrm{hr}$ and $3 \mathrm{hr}$, and (iii) period of postoperative $12 \mathrm{hr}$ and $24 \mathrm{hr}$.

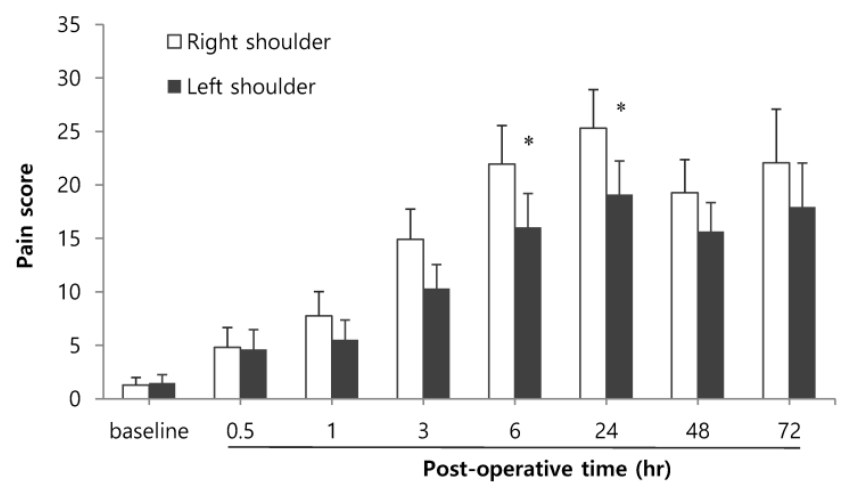

Figure 4. Bilateral shoulder pains. * Indicates a statistically significant difference compared with the right shoulder $(p<0.05)$. The pain score was expressed using a $100 \mathrm{~mm}$ visual analog scale (VAS).

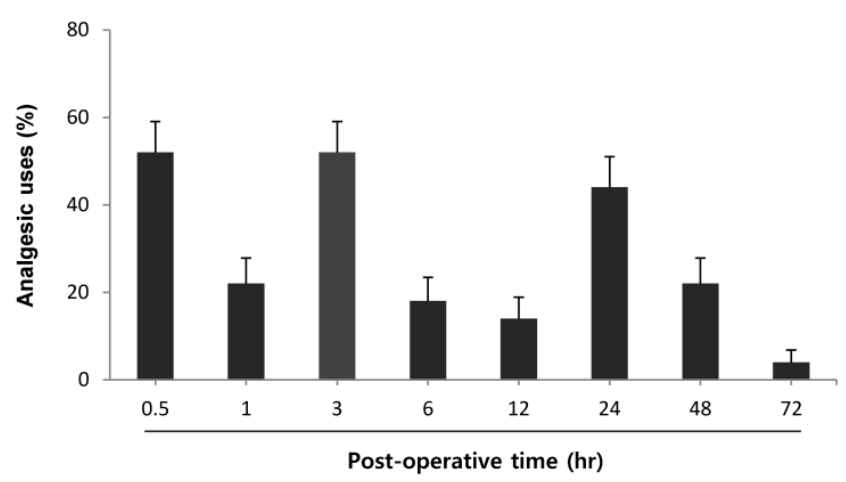

Figure 5. The percentage of patients using additional analgesics. $X$-axis is defined by the period of time. For example, postoperative $0.5 \mathrm{hr}$ in the graph means the entire period of PACU arrival and postoperative $30 \mathrm{~min}$.

\section{Discussion}

This prospective observational study described the pain characteristics in detail during the first postoperative $72 \mathrm{hr}$ in patients undergoing the TLH. Incisional and visceral pains were most intense $30 \mathrm{~min}$ after surgery, gradually decreasing thereafter. Visceral pain dominated over incisional pain constantly for postoperative $72 \mathrm{hr}$. Whereas, shoulder pain was less severe on the day of operation, and increased to the maximum severity at postoperative $24 \mathrm{hr}$. Additionally, the severity of pain was influenced by ordinary exercise habit, which alleviated overall pain and shoulder pain on the operation day or postoperative $24 \mathrm{hr}$; however, abdominal visceral pain was not found to be associated with exercise habit status.

The mechanism of laparoscopy-induced shoulder pain is generally considered as referred pain. The phrenic nerve (C3-5) innervates the diaphragmatic pleural surface and connects with the supraclavicular nerve (C3-4), which conducts sensory input of the acromium process. As referred pain arises through convergence on the spinothalamic tract, [18] the diaphragm irritation leads to referred pain in the top of the shoulder. Although the exact mechanism of diaphragm irritation related to pneumoperitoneum has not yet been clarified, [11] the cause is postulated to be due to $\mathrm{H}_{2} \mathrm{CO}_{3}$ conversion from $\mathrm{CO}_{2}$, sub-diaphragmatic $\mathrm{CO}_{2}$ entrapment, and retained fluid or blood. Also rapid distension of the peritoneum may be associated with overstretching of the diaphragmatic muscle fibers, tearing of blood vessels, traumatic traction of nerves, or release of inflammatory mediators. Moreover, shoulder pain after TLH may be intensified by intraoperative position and external compression, for instance, trendelenburg position has been associated with the development of the brachial plexus injury. [19] This injury results from severe stretching and compression of the plexus between the clavicle and first rib during caudad pressure on the shoulder by the shoulder brace. [20] The stretching or compression of a nerve may cause interruption of the blood supply, edema, and ischemia to a nerve, resulting in intra-neural hemorrhage or necrosis, or conduction block. [21] Alongside this, the use of anesthetics and muscle relaxants decrease muscle resistance to external pressure, and so prevent the patient from correcting uncomfortable positions. [22]

In this study, the incidence of shoulder pain was high, up to approximately $90 \%$ for the postoperative $72 \mathrm{hr}$ in patients undergoing TLH. Also, among the patients that received analgesics at postoperative 24 $\mathrm{hr}$, two-thirds of patients complained of shoulder pain 
that was similar to, or stronger than, abdominal pain. A high incidence of shoulder pain might be influenced by patient gender, in addition to pneumoperitoneum and intraoperative position. Some reports have suggested that women may have a lower pain threshold and feel higher unpleasantness than men. [23,24] After laparoscopic cholecystectomy, women exhibit higher pain scores and required more analgesics than men. [11,25]

In the current study, visceral pain was more intense than incisional pain at all times. This pattern is similar to those after laparoscopic fundoplication, laparoscopic ventral hernia repair, and laparoscopic inguinal hernia repair. [12-14] However, this is in contrast with the pain pattern observed in patients undergoing laparoscopic cholecystectomy, who complained more of incisional pain than visceral pain. [18] In addition, TLH showed different dominance of visceral, incisional, and shoulder pains, compared with other laparoscopic procedures. Shoulder pain developed after TLH stayed intense from the morning on the following day, which may be related to $\mathrm{CO}_{2}$ persisting for $>48$ hours in the subdiaphragmatic space after laparoscopy. [26] This pattern was not reported in other studies, in which visceral and incisional pain was dominant compared to shoulder pain. [10,12-14]

Therefore, considering the high incidence and intensity of shoulder pain after TLH, there is a need for individually customized analgesic treatment for TLH patients, rather than generalized analgesic treatment. [9] The shoulder pain after thoracotomy was relatively resistant to IV opioids, and increasing the epidural infusion for adequate analgesia resulted in an unacceptable level of sedation and hypotension. [27] Alternatively, nonsteroidal antiinflammatory drugs (NSAID) in relatively large doses might be effective. $[27,28]$ In patients undergoing gynecological laparoscopic surgery, a prophylactic NSAID patch was effective for the relief of shoulder tip pain. [29] Recently, perioperative pregabalin also significantly reduced postoperative laparoscopic shoulder pain. [30]

A past history of delivery or cesarean section increases the risk of chronic pain after hysterectomy; [31] however, in this study, delivery or cesarean history did not influence the acute pain after TLH for the postoperative $72 \mathrm{hr}$.

In the past, laparoscopic surgery was a relative contraindication to the obese patient because of the prolonged operation time, difficult surgical approach, and other anesthetic comorbidities. [32] Although it is still controversial, [32-34] the laparoscopic approach has been recommended for obese patients in reference to feasibility and safety, in terms of surgical outcomes, laparotomy conversion rate, complication rate, operation time and duration of hospitalization, through surgical technique improvement. [33] Obesity has been associated with pain sensitivity, although with some conflicting results. [35,36] In this study, both overweight and obesity did not increase the incisional, visceral, or shoulder pains after TLH, which is consistent with a previous study. [34]

Preoperative exercise therapy can reduce the length of hospital stay or postoperative complications following cardiac or abdominal surgery, even if the period of exercise was short, such as just 2 weeks. [37] Exercise therapy also improves functional status or muscle strength in joint replacement surgery; however, there are very few reports regarding whether the ordinary exercise habits before surgery influence postoperative pain. In contrast with the current study, a report revealed that ordinary physical activity is associated with decreased pressure pain threshold, [38] but the report did not discern between occupational and leisure-time physical activities. [39] In the current study, ordinary exercise habit applies to leisure-time physical activity such as fitness, swimming, golf, yoga, aerobics and climbing. Physical activity at leisure is dynamic contractions of large muscle groups increasing whole-body metabolism and cardiac output, with voluntary resting upon personal urge due to fatigue or stress. [40] In addition to well documented health promotion through physical activity, [41,42] it reduced the pain degree after surgery and influenced the quality of recovery in this study.

This study demonstrated the timing and pattern of shoulder pain in patients undergoing TLH. Shoulder pain was most intense at postoperative 24 $\mathrm{hr}$, and was associated with the high level of analgesic request. Right shoulder pain was found to be more severe than left shoulder pain, and the intensity of pain did not increase during activity. In addition, preoperative exercise habit of patients increased the threshold of shoulder pain, and consequently reduced overall postoperative pain. Unexpectedly, when being questioned about postoperative pain, most patients responded only regarding abdominal pain, as they considered the shoulder pain unrelated to surgery. In this regard, notice and comprehension of shoulder pain through the current study may lead to a closer understanding of patients undergoing TLH.

In the abdomen, incisional pain was felt as pricking and increased in activity over postoperative time, but intensity was relatively low. Visceral pain was very intense and heavy/dull inner pain, which was associated with intestinal mobility and periodically aggravated by gaseous intestine. Apart from these 2 pains, there was another type of 
abdominal pain that widely covered the solar plexus to the flank, and it was accompanied by strong muscle tightness as felt after intense exercise, such as 100 sit-ups, and increased pain during activity. Most patients had perineal pain and one-third of patients showed higher pain scores in the perineum than in the abdomen. Perineal pain was not pricking but uncomfortable; however, once developed, was more unbearable than abdominal pain.

In conclusion, pain after TLH showed considerably different duration, severity, and characteristics, compared with other laparoscopic procedures. Especially, shoulder pain was most intense at postoperative $24 \mathrm{hr}$, and the intensity was associated with the prior exercise habit of patients and the high level of analgesic request. This study helps better comprehend the postoperative pain of gynecological patients. Future study should consider the pain after TLH compared with other types of laparoscopic procedures.

\section{Competing Interests}

The authors have declared that no competing interest exists.

\section{References}

1. Nieboer TE, Johnson N, Lethaby A, Tavender E, Curr E, Garry R, et al. Surgical approach to hysterectomy for benign gynaecological disease. Cochrane Database Syst Rev 2009. doi:10.1002/14651858.CD003677.pub4.(3):CD003677.

2. Gerbershagen HJ, Aduckathil S, van Wijck AJ, Peelen LM, Kalkman CJ, Meissner W. Pain intensity on the first day after surgery: a prospective cohort study comparing 179 surgical procedures. Anesthesiology 2013; 118(4):934-44.

3. Ekstein P, Szold A, Sagie B, Werbin N, Klausner JM, Weinbroum AA. Laparoscopic surgery may be associated with severe pain and high analgesia requirements in the immediate postoperative period. Ann Surg 2006; 243(1):41-6.

4. Woolf CJ. Central sensitization: implications for the diagnosis and treatment of pain. Pain 2011; 152(3 Suppl):S2-15.

5. Bisgaard T, Rosenberg J, Kehlet H. From acute to chronic pain after laparoscopic cholecystectomy: a prospective follow-up analysis. Scand J Gastroenterol 2005; 40(11):1358-64.

6. Alfieri S, Amid PK, Campanelli G, Izard G, Kehlet H, Wijsmuller AR, et al. International guidelines for prevention and management of post-operative chronic pain following inguinal hernia surgery. Hernia 2011; 15(3):239-49.

7. Tolver MA, Rosenberg J, Bisgaard T. Early pain after laparoscopic inguinal hernia repair. A qualitative systematic review. Acta Anaesthesiol Scand 2012; 56(5):549-57.

8. Kehlet H. Procedure-specific postoperative pain management. Anesthesiol Clin North America 2005; 23(1):203-10.

9. Kehlet H, Wilkinson RC, Fischer HB, Camu F. PROSPECT: evidence-based, procedure-specific postoperative pain management. Best Pract Res Clin Anaesthesiol 2007; 21(1):149-59.

10. Bisgaard T, Klarskov B, Rosenberg J, Kehlet H. Characteristics and prediction of early pain after laparoscopic cholecystectomy. Pain 2001; 90(3):261-9.

11. Kandil TS, El Hefnawy E. Shoulder pain following laparoscopic cholecystectomy: factors affecting the incidence and severity. J Laparoendosc Adv Surg Tech A 2010; 20(8):677-82.

12. Eriksen JR, Poornoroozy P, Jorgensen LN, Jacobsen B, Friis-Andersen HU, Rosenberg J. Pain, quality of life and recovery after laparoscopic ventral hernia repair. Hernia 2009; 13(1):13-21.

13. Tolver MA, Strandfelt P, Rosenberg J, Bisgaard T. Pain characteristics after laparoscopic inguinal hernia repair. Surg Endosc 2011; 25(12):3859-64.

14. Bisgaard T, Stockel M, Klarskov B, Kehlet H, Rosenberg J. Prospective analysis of convalescence and early pain after uncomplicated laparoscopic fundoplication. Br J Surg 2004; 91(11):1473-8.

15. Klimek M, Ubben JF, Ammann J, Borner U, Klein J, Verbrugge SJ. Pain in neurosurgically treated patients: a prospective observational study. J Neurosurg 2006; 104(3):350-9.

16. Zirak N, Soltani G, Hafizi L, Mashayekhi Z, Kashani I. Shoulder pain after caesarean section: comparison between general and spinal anaesthesia. J Obstet Gynaecol 2012; 32(4):347-9.
17. Glickman ME, Rao SR, Schultz MR. False discovery rate control is a recommended alternative to Bonferroni-type adjustments in health studies. J Clin Epidemiol 2014; 67(8):850-7.

18. Bolser DC, Hobbs SF, Chandler MJ, Ammons WS, Brennan TJ, Foreman RD. Convergence of phrenic and cardiopulmonary spinal afferent information on cervical and thoracic spinothalamic tract neurons in the monkey: implications for referred pain from the diaphragm and heart. J Neurophysiol 1991; 65(5):1042-54.

19. Raffan AW. Post-operative paralysis of the brachial plexus. Br Med J 1950; 2(4671):149.

20. Jackson L, Keats AS. MECHANISM OF BRACHIAL PLEXUS PALSY FOLLOWING ANESTHESIA. Anesthesiology 1965; 26:190-4.

21. Dahlin LB, Rydevik B, McLean WG, Sjostrand J. Changes in fast axonal transport during experimental nerve compression at low pressures. Exp Neurol 1984; 84(1):29-36.

22. Winfree CJ, Kline DG. Intraoperative positioning nerve injuries. Surg Neurol 2005; 63(1):5-18; discussion

23. Frot M, Feine JS, Bushnell MC. Sex differences in pain perception and anxiety. A psychophysical study with topical capsaicin. Pain 2004; 108(3):230-6.

24. Fillingim RB, Maixner W, Kincaid S, Silva S. Sex differences in temporal summation but not sensory-discriminative processing of thermal pain. Pain 1998; 75(1):121-7

25. Uchiyama K, Kawai M, Tani M, Ueno M, Hama T, Yamaue H. Gender differences in postoperative pain after laparoscopic cholecystectomy. Surg Endosc 2006; 20(3):448-51.

26. Joris J, Cigarini I, Legrand M, Jacquet N, De Groote D, Franchimont P, et al. Metabolic and respiratory changes after cholecystectomy performed via laparotomy or laparoscopy. Br J Anaesth 1992; 69(4):341-5.

27. Scawn ND, Pennefather SH, Soorae A, Wang JY, Russell GN. Ipsilateral shoulder pain after thoracotomy with epidural analgesia: the influence of phrenic nerve infiltration with lidocaine. Anesth Analg 2001; 93(2):260-4, 1st contents page.

28. Burgess FW, Anderson DM, Colonna D, Sborov MJ, Cavanaugh DG. Ipsilateral shoulder pain following thoracic surgery. Anesthesiology 1993; 78(2):365-8.

29. Hong JY, Lee IH. Suprascapular nerve block or a piroxicam patch for shoulder tip pain after day case laparoscopic surgery. Eur J Anaesthesiol 2003; 20(3):234-8.

30. Nutthachote $\mathrm{P}$, Sirayapiwat $\mathrm{P}$, Wisawasukmongchol W, Charuluxananan S. A randomized, double blind, placebo-controlled trial of oral pregabalin for the relief of shoulder pain following laparoscopic gynecologic surgery. J Minim Invasive Gynecol 2014. doi:10.1016/j.jmig.2014.01.018.

31. Brandsborg B, Nikolajsen L, Hansen CT, Kehlet H, Jensen TS. Risk factors for chronic pain after hysterectomy: a nationwide questionnaire and database study. Anesthesiology 2007; 106(5):1003-12.

32. Camanni M, Bonino L, Delpiano EM, Migliaretti G, Berchialla P, Deltetto F. Laparoscopy and body mass index: feasibility and outcome in obese patients treated for gynecologic diseases. J Minim Invasive Gynecol 2010; 17(5):576-82.

33. Litta P, Fabris AM, Breda E, Bartolucci C, Conte L, Saccardi C, et al. Laparoscopic surgical staging of endometrial cancer: does obesity influence feasibility and perioperative outcome? Eur J Gynaecol Oncol 2013; 34(3):231-3.

34. Morgan-Ortiz F, Soto-Pineda JM, Lopez-Zepeda MA, Peraza-Garay Fde J. Effect of body mass index on clinical outcomes of patients undergoing total laparoscopic hysterectomy. Int J Gynaecol Obstet 2013; 120(1):61-4.

35. Khimich S. Level of sensitivity of pain in patients with obesity. Acta Chir Hung 1997; 36(1-4):166-7

36. Maffiuletti NA, Morelli A, Martin A, Duclay J, Billot M, Jubeau M, et al. Effect of gender and obesity on electrical current thresholds. Muscle Nerve 2011; 44(2):202-7.

37. Valkenet K, van de Port IG, Dronkers JJ, de Vries WR, Lindeman E, Backx FJ. The effects of preoperative exercise therapy on postoperative outcome: a systematic review. Clin Rehabil 2011; 25(2):99-111.

38. Zhang Y, Zhang S, Gao Y, Tan A, Yang X, Zhang H, et al. Factors associated with the pressure pain threshold in healthy Chinese men. Pain Med 2013; 14(9):1291-300.

39. Holtermann A, Hansen JV, Burr H, Sogaard K, Sjogaard G. The health paradox of occupational and leisure-time physical activity. Br J Sports Med 2012; 46(4):291-5.

40. American College of Sports Medicine Position Stand. The recommended quantity and quality of exercise for developing and maintaining cardiorespiratory and muscular fitness, and flexibility in healthy adults. Med Sci Sports Exerc 1998; 30(6):975-91.

41. Leitzmann MF, Park Y, Blair A, Ballard-Barbash R, Mouw T, Hollenbeck AR, et al. Physical activity recommendations and decreased risk of mortality. Arch Intern Med 2007; 167(22):2453-60.

42. Haskell WL, Lee IM, Pate RR, Powell KE, Blair SN, Franklin BA, et al. Physical activity and public health: updated recommendation for adults from the American College of Sports Medicine and the American Heart Association. Med Sci Sports Exerc 2007; 39(8):1423-34. 